\title{
Serum Insulin Levels in School Children Aged 9-12 in Westland, Holland
}

\author{
C. du V. Florey, C. Lowy and S. Uppal \\ Department of Community Medicine and Department of Chemical Pathology, St. Thomas' Hospital Medical School, London, England and \\ Department of Cardiology, University of Leiden, Leiden, The Netherlands
}

\begin{abstract}
Summary. In a study of risk factors for cardiovascular disease in 2388 school children aged 9-12 years carried out in Westland, Holland, serum insulin levels at one hour after an oral challenge of $50 \mathrm{~g}$ glucose were measured in a systematically selected subsample of 715 children. The distribution and associations of serum insulin in these children are described. The mean insulin values were $24.6 \mu \mathrm{U} / \mathrm{ml}$ for boys and $32.0 \mu \mathrm{U} / \mathrm{ml}$ for girls. The difference between these means was statistically significant and remained so even after taking measures of adiposity into account. Insulin values were positively related to levels of plasma sugar and systolic blood pressure in both sexes.
\end{abstract}

Key words: Insulin, insulin resistance, blood glucose, epidemiology, diabetes mellitus, child.

The Westland Study of school children was set up under the auspices of the World Health Organization, and was carried out between April and June, 1973. The study had two main objectives, one to investigate the effects of air pollution on children's respiratory tracts and the other to estimate the levels and characteristics of factors which, when elevated, are thought to predispose to coronary artery disease in adults. Blood measurements included cholesterol and sugar, estimated in plasma one hour after a $50 \mathrm{~g}$ oral load of glucose. We extended the laboratory determinations to include serum insulin since this has been suggested as a risk factor for coronary disease and there are few published accounts of its levels in population samples of children. In this report we describe its distribution and relationship to other variables.

\section{Materials and Methods}

The total study population consisted of 2480 Dutch school children between the ages of 9 and 12 (1260 boys and 1220 girls), who were on the lists of the fourth and fifth classes of all 41 schools in the Westland region. Of these, 1214 boys $(96.4 \%)$ and 1174 girls $(96.2 \%)$ were seen.

The cardiac study consisted of two parts, one a screening examination in the schools and the other the collection of data about the children's health by a questionnaire posted to the parents. The questionnaire was completed for all the children seen in school. A detailed account of the methods and response is given elsewhere [1].

At the examination the children were registered and then given $50 \mathrm{~g}$ glucose to drink (they were not specifically asked to come in the fasting state). Anthropometric measurements were then taken (height, weight on a lever balance, triceps and subscapular skinfold with Harpenden calipers, and arm circumference) followed by blood pressure measured with a random zero sphygmomanometer (Hawksley). One hour after taking the oral glucose, blood was taken from the antecubital vein for determination of serum cholesterol and plasma sugar. Serum cholesterol was measured by the Huang method [2] and plasma sugar by Hoffman's method [3].

Those vials which had not previously been emptied of serum for other tests were ordered by serial number. A 1-in-3 systematic sample of these remaining vials was drawn. This provided 715 vials which were transported to London for insulin estimations.

Insulin measurements were carried out on serum samples, using a radioimmunoassay based on the Morgan and Lazarow method [4]. ${ }^{125}$ I-insulin, prepared by Novo Laboratories, was used as a tracer. 
Table 1. Mean values of ten variables compared between those whose serum insulin levels were and were not measured

Number of observations in brackets

\begin{tabular}{lrrl}
\hline Variable & $\begin{array}{l}\text { Insulin } \\
\text { subsample } \\
\left(\mathrm{N}_{\max }=715\right)\left(\mathrm{N}_{\max }=1673\right)\end{array}$ & $\begin{array}{l}\text { Remainder } \\
\text { (t-test })\end{array}$ \\
\hline Height (cms) & $146.3(714)$ & $146.0(1669)$ & $\mathrm{NS}$ \\
Weight (kg.) & $36.0(715)$ & $35.8(1669)$ & $\mathrm{NS}$ \\
Triceps skfld. (mm.) & $10.4(715)$ & $10.3(1673)$ & $\mathrm{NS}$ \\
Subscap. skfld. (mm.) & $6.9(714)$ & $6.8(1672)$ & $\mathrm{NS}$ \\
Arm circum. (cms.) & $19.8(715)$ & $19.7(1672)$ & $\mathrm{NS}$ \\
Systolic BP (mm.Hg.) & $101.7(715)$ & $100.5(1673)$ & $<0.05$ \\
Diastolic BP (mm.Hg.) & $57.2(715)$ & $56.5(1673)$ & $\mathrm{NS}$ \\
Age (yrs.) & $10.8(715) 10.8(1673)$ & $\mathrm{NS}$ \\
Cholesterol (mg/100 ml) $188.9(715) 189.8(1625)$ & $\mathrm{NS}$ \\
Pl. sugar (mg/100 ml) & $112.4(714) 110.8(1586)$ & $\mathrm{NS}$ \\
\hline Mahalanobis D $=0.01$ & $\mathrm{~F}_{(10,2287)}=0.86$ & $\mathrm{p} \bumpeq 0.50$ \\
\hline
\end{tabular}

NS $=p>.05 \quad$ Not significant.

Table 2. Distribution of serum insulin by sex

\begin{tabular}{|c|c|c|c|c|}
\hline $\begin{array}{l}\text { Serum } \\
\text { Insulin } \\
(\mu \mathrm{U} / \mathrm{ml})\end{array}$ & $\begin{array}{l}\text { Boys } \\
\text { No. }\end{array}$ & Cum \% & $\begin{array}{l}\text { Girls } \\
\text { No. }\end{array}$ & Cum \% \\
\hline 0 & 12 & 3.2 & 2 & 0.6 \\
\hline $5-$ & 41 & 14.1 & 16 & 5.3 \\
\hline $10-$ & 52 & 28.0 & 28 & 13.5 \\
\hline $15-$ & 52 & 41.9 & 46 & 23.1 \\
\hline $20-$ & 54 & 56.3 & 50 & 41.8 \\
\hline $25-$ & 43 & 67.7 & 56 & 58.2 \\
\hline $30-$ & 41 & 78.7 & 36 & 68.8 \\
\hline $35-$ & 27 & 85.9 & 21 & 75.0 \\
\hline $40-$ & 22 & 91.7 & 22 & 81.5 \\
\hline $45-$ & 8 & 93.9 & 10 & 84.4 \\
\hline 50 & 11 & 96.8 & 15 & 88.8 \\
\hline $55-$ & 2 & 97.3 & 6 & 90.6 \\
\hline $60-$ & 1 & 97.6 & 7 & 92.7 \\
\hline $65-$ & 4 & 98.7 & 7 & 94.7 \\
\hline $70-$ & 3 & 99.5 & 4 & 95.9 \\
\hline $75-$ & 0 & 99.5 & 3 & 96.8 \\
\hline $80-$ & 2 & 100.0 & 4 & 97.9 \\
\hline $85-89$ & - & & 5 & 99.4 \\
\hline 117 & - & & 1 & 99.7 \\
\hline 216 & - & & 1 & 100.0 \\
\hline Total & 375 & & 340 & \\
\hline Mean & 24.64 & & 32.0 & \\
\hline S.D. & 14.42 & & 20.75 & \\
\hline
\end{tabular}

Separation of antibody-bound insulin from free insulin was carried out using dextran charcoal. The solutions for determining the standard curve were prepared from human insulin given by the British Medical Research Council and coded 66/304. Insulin-free serum was added to these solutions so that each assay tube had identical quantities of serum present. The unknown samples were estimated in 12 assays. A
Table 3. Simple correlation coefficients between serum insulin ${ }^{\mathrm{a}}$ and other variables, by sex

\begin{tabular}{lll}
\hline & \multicolumn{2}{l}{ Correlation Coefficients } \\
Voys & Girls \\
& $\mathrm{N}=375^{\mathrm{c}}$ & $\mathrm{N}=338^{\mathrm{c}}$ \\
\hline Height & 0.10 & $0.16^{\mathrm{b}}$ \\
Weight & $0.19^{\mathrm{b}}$ & $0.19^{\mathrm{b}}$ \\
Triceps skinfold & $0.13^{\mathrm{b}}$ & 0.04 \\
Subscap. skinfold & $0.16^{\mathrm{b}}$ & $0.17^{\mathrm{b}}$ \\
Systolic B.P. & $0.18^{\mathrm{b}}$ & $0.24^{\mathrm{b}}$ \\
Diastolic B.P. & 0.05 & 0.13 \\
Cholesterol & 0.02 & 0.00 \\
Plasma sugar & $0.37^{\mathrm{b}}$ & $0.43^{\mathrm{b}}$ \\
Age & 0.03 & $0.16^{\mathrm{b}}$ \\
\hline
\end{tabular}

a The distribution of serum insulin was made normal with the transformation $\log$ (insulin +7 ). The transformed values were used in the calculation of the correlation coefficients.

${ }^{\mathrm{b}} \mathrm{p}<0.01$

c The correlation with plasma sugar for boys was based on 374 observations and the correlations for height and subscapular skinfold for girls on 337 observations.

quality control serum was included in each assay and measured at two dilutions, $0.1 \mathrm{ml}$ and $0.05 \mathrm{ml}$. The coefficient of variation of this serum was $11 \%$ at 0.1 $\mathrm{ml}$. The assays of the unknown samples were carried out in duplicate using $0.1 \mathrm{ml}$ of serum. Two samples, because of their high values, were reassayed using $0.05 \mathrm{ml}$ of serum. The lower detection limit for this assay was $3.0 \mu \mathrm{U} / \mathrm{ml}$.

The subsample of 715 school children appeared to be representative of the total sample as shown by individual comparisons of mean values of all the variables listed in Table 1, and by comparison of all these variables simultaneously, using the Mahalanobis $\mathrm{D}^{2}$ statistic (a type of multivariate t-test) [5].

\section{Results}

The distributions of insulin values are given in Table 2 for boys and girls separately. In the data for the girls there were two observations which were excessively high (more than 4 standard deviations from the mean) and which seemed to be separated from the rest of the distribution. These two values have been omitted from all subsequent analyses because of their profoundly disturbing effects on the statistical procedures. Repeat determinations on these sera yielded the same high concentrations of insulin. ${ }^{1}$

1 The girl with $216 \mu \mathrm{U} / \mathrm{ml}$ of serum insulin was aged 11 . Her measurements for triceps and subscapular skinfold, and systolic and diastolic blood pressure were all above the 85 th percentile for her age and sex and her plasma sugar was above the 95th percentile. The measurements for the other girl, aged 10 , were under the 50th percentile for her age and sex for both skinfolds and systolic and diastolic pressure, but above the 95 th percentile for plasma sugar. 
With these two values omitted, the mean ( \pm standard deviation) for girls was $31.2 \mu \mathrm{U} / \mathrm{ml} \pm 17.2$. This mean was significantly greater than the mean for boys $(24.6 \mu \mathrm{U} / \mathrm{ml} \pm 14.4, \mathrm{p}<.001)$. Diurnal variation in insulin levels did not account for this difference, since the girls' insulin levels were significantly higher than those of the boys whether they were examined in the morning or the afternoon ( $69 \%$ of the boys and $66 \%$ of the girls were examined in the morning; the average age of all four groups defined by sex and time of examination was 10.8 years). In both sexes the insulin values were directly related to weight and, to some extent, to the skinfolds (Table 3). Since the girls had significantly larger skinfolds than the boys, measuring, respectively, 11.6 and $9.3 \mathrm{~mm}$ for triceps, 7.6 and 6.2 $\mathrm{mm}$ for subscapular skinfold, the difference in mean insulin levels might have been due to the girls' greater adiposity.

Figure 1 shows the relationship between mean one hour insulin values by sex and by size of subscapular skinfold. The data were analysed using an analysis of variance for tables with unequal numbers in their cells [6].

The significance testing in this analysis is only valid if the relationship between two variables follows the same pattern for the two groups being compared (no interaction). If they do not have the same pattern (i.e. they are not parallel) then the test for interaction will give a statistically significant result and the rest of the analysis must be ignored. We found no significant interaction on our data $(p>0.90)$. The analysis showed that there was a significant relation between insulin values and skinfold measurements after adjusting for the sex differences $\left(\mathrm{F}_{(4,703)}=4.4\right.$, $\mathrm{p}$ $<0.005)$ and that the insulin values for girls were significantly higher than those for the boys after adjusting for skinfold $\left(\mathrm{F}_{(1,703)}=20.1, \mathrm{p}<0.0005\right)$. The analysis was carried out using the original data and also using a log transformation of insulin which normalised the distributions $(\log ($ insulin +7$))$. The results were very similar in terms of probability statements. The higher serum insulin values in girls could not be ascribed to differences in plasma sugar since the mean plasma sugar value for girls was less than that for boys (110.2 and $112.2 \mathrm{mg} / 100 \mathrm{ml}$ respectively).

Serum insulin in girls and subscapular skinfold in both sexes were related to age. To remove any effect of age on the results, the data were reanalysed separately for ten and eleven year olds. There was no significant interaction in either analysis and the differences between the sexes were still highly significant $(p<0.005)$. Using the same method, significant differences were also found between the insulin levels in boys and girls examined in the morning $(p<0.0005)$ and in the afternoon $(\mathrm{p}<0.025)$. The interaction terms were not significant.

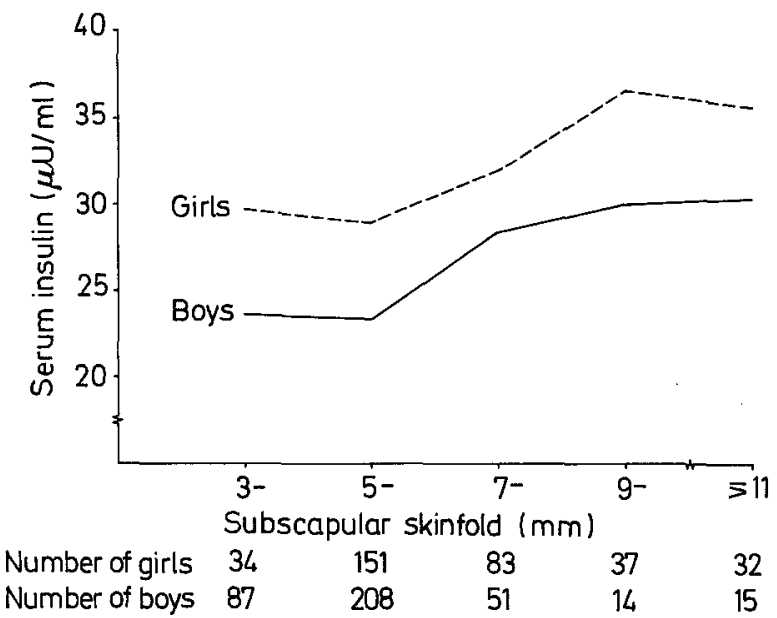

Fig. 1. Mean serum insulin at one h by subscapular skinfold in boys and girls

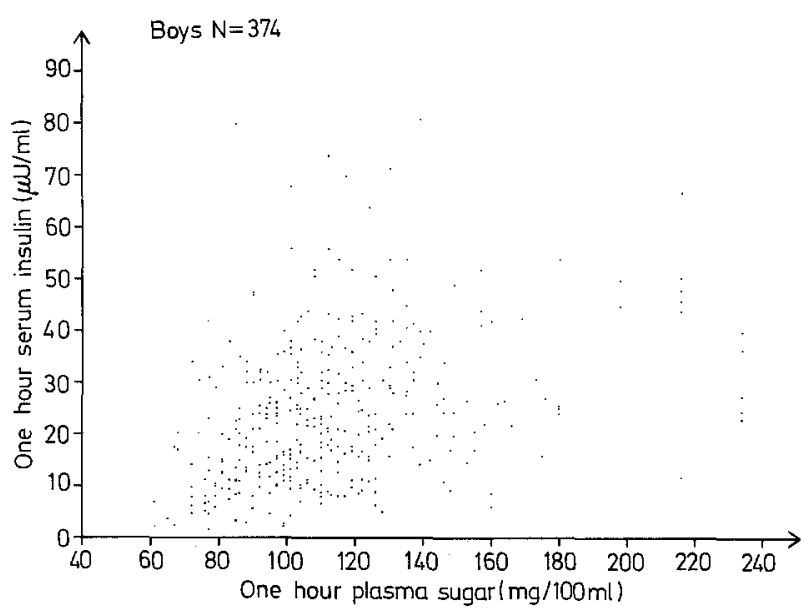

Girls $N=338$

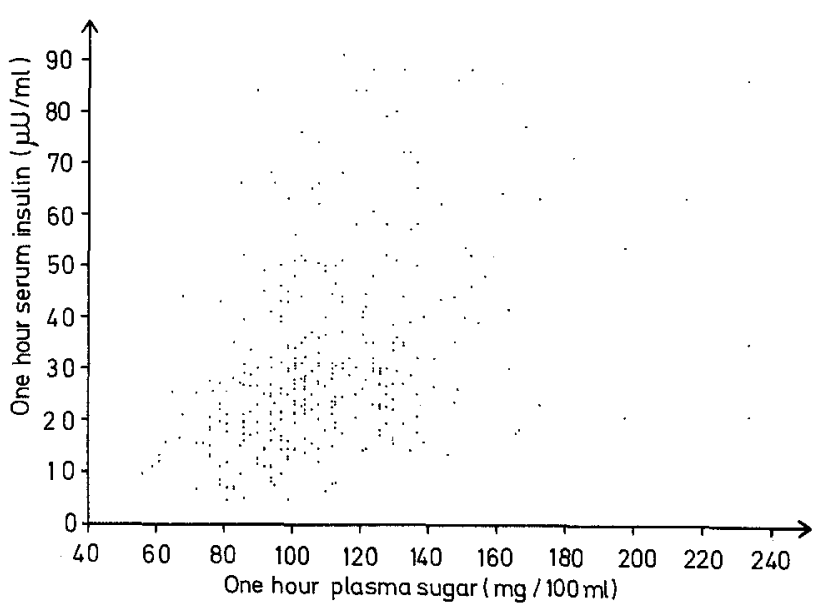

Fig. 2. Scatter diagrams of serum insulin by plasma sugar levels at one h plotted by computer. (In each diagram, 13 of the points represent two individuals who had precisely the same insulin and sugar values. The computer program did not allow these points to be distinguished.) 
Significant positive correlations were also found between serum insulin and plasma sugar for boys and girls. Figure 2 shows that, at low levels of plasma sugar, only low levels of serum insulin are found, but with increasing sugar the scatter of insulin values widens. A greater proportion of the girls had high insulin values. The simple correlation between insulin and systolic blood pressure was also significant, but the partial correlation between these variables, allowing for plasma sugar levels, was not significant [7].

There were only two children in the whole survey sample who were reported as diabetic by their parents and neither fell in the insulin sub sample. Nine chil dren with plasma sugar levels above $220 \mathrm{mg} / 100 \mathrm{ml}$ were referred to their general practitioners for a complete glucose tolerance test. Five came for re-examination and none was found to have a diabetic curve.

\section{Discussion}

We have described the distribution of serum insulin one hour after glucose challenge in a defined, non-institutionalised child population. We believe that no such population reference data have been published and have been unable to find any data for children based on population studies which are epidemiologically sound. However, one large group has been described [8] which consisted of 125 children, selected in an unspecified way from a local community in New York City, made up of a mixture of Puerto Rican $(79 \%)$, negro $(11 \%)$ and white $(10 \%)$ children aged $1 \frac{1}{2}-12$ years. A full glucose tolerance test was given; at one hour the mean serum insulin level was 32.5 $\mu \mathrm{U} / \mathrm{ml}$, and the mean capillary blood sugar 107.8 $\mathrm{mg} / 100 \mathrm{ml}$. The children were between the 25 th and 75 th percentile for weight by standard tables and were not obese. No relation between insulin level and age was found.

Other studies have varied in size from about 50 [9, 10] down to six [11] and were composed of children from students' families and local schools, from hospitalised groups defined as "normal" [12-16], and from normals without further description $[11,17,18]$. Although the normality or representativeness of the children in these studies might be questioned, a frequent finding was the lack of association of serum insulin levels with age. Nevertheless, relationships with age have been reported. A decline has been described [19] in fasting levels from $1 \frac{1}{2}-2$ years to 3-9 years, with an increase thereafter, although this has been contradicted elsewhere, [15] with evidence of a straight line increase from age three months to 11-15 years. Two other studies [14,20] of children have suggested that serum insulin levels are higher in older children at most or all of the sampling times in a full GTT. However, in none of these studies were the results given for boys and girls separately, although our own finding of an association with age for girls, but not for boys, indicates that such a separation is necessary.

We have shown also that there is a difference between boys and girls in the absolute values of serum insulin. In the studies of children cited above and in many studies of adults it has been assumed that no difference between the sexes existed and consequently the data have not been presented for males and females separately. It is clear from our results that, at least in children, the differences are fairly small and that they are not likely to be detected in small samples of individuals. Detection of the difference has probably been made more difficult still because of the lack of appropriate population sampling techniques in the majority of studies which include one hour insulin measurements.

However, there are four epidemiological studies in adults [21-26] in which insulin levels at one hour have been reported for samples drawn from defined populations. In all four there was evidence that insulin levels at one hour were higher in women than men. Since women are on average more obese than men it was possible that the differences in serum insulin levels between the sexes found in these studies were merely a reflection of differences in adiposity. In two of the studies $[19,22]$ this explanation was not investigated. The differences in insulin levels found in an Australian study were attributed to differences in triceps skinfold, though the description of the statistical method used to reach this conclusion suggested that alternative interpretations were possible [24]. In a study in Jamaica one of us $(\mathrm{CF})$, working with other colleagues, carried out the same analysis as in the present paper [25] and found that the difference between the insulin values of men and women was highly significant.

The data suggest that the females were more insulin resistant than the males, and that this resistance was not entirely explained by differences in adiposity in at least two of the studies. It is known that the levels of circulating oestrogens $[27,28]$ and growth hormone [29] are both positively associated with insulin resistance. Oestrogen levels in giris immediately before the menarche are low, but nevertheless higher than in boys of the same age [30,31], and growth hormone levels are higher in women than men [32,33]. It is thus possible that the higher serum insulin values in the girls in our study are due to higher circulating oestrogen and growth hormone concentrations, and that the increase in insulin levels with age seen only in girls is a reflection of increasing oestrogen levels with the onset of puberty.

In the light of these findings it is clear that insulin 
levels should be reported by sex and that allowance be made for the effect of sex in comparisons of insulin levels between groups.

Acknowledgements. We thank Professor A.C. Arntzenius and Professor J.H. de Haas for their help and encouragement in organising and carrying out this study, Dr. B. Grab of WHO Headquarters, Geneva, for providing the data tape, and Mr. A. Sadler for making the insulin determinations. We also thank Professor R.M. Acheson and Professor F.H. Epstein for their helpful comments on the manuscript. The Netherlands Heart Foundation provided financial support for the survey.

\section{References}

1. Uppal, S.C.: Coronary heart disease. Risk pattern in Dutch youth. M.D. Thesis, Leiden 1974

2. Huang, T.C., Chan, C.P., Weffler, V., Raferty, A. A.: A stable reagent for the Liebermann Burchard reaction. Analyt. Chem. 33, 1405-1407 (1961)

3. Hoffman, W. S.: A rapid photoelectric method for the determination of glucose in blood and urine. J. biol. Chem. 120, 51-55 (1937)

4. Morgan, C.R., Lazarow, A.: Immunoassay of insulin: Two antibody system. Plasma insulin levels of normal, subdiabetic and diabetic rats. Diabetes 12, 115-126 (1963)

5. Rao, C. R.: Linear statistical inference and its applications. p. 480. New York: Wiley 1965

6. Snedecor, G. W., Cochran, W.G.: Statistical methods, 6th Ed., p. 484. Iowa: Iowa State Univ. 1967

7. Florey, C. du V., Uppal, S., Lowy, C.: Relation between blood pressure, weight, and plasma sugar and serum insulin levels in schoolchildren aged 9-12 years in Westland, Holland. Brit. med. J. 1976 I, 1368-1371

8. Cole, H. S., Epel, R.: Serum insulin and growth hormone values in children during the oral glucose tolerance test. Diabetes 21 , 16-22 (1972)

9. Guthrie, R.A., Guthrie, D. W., Murthy, D. Y. N. Jackson, R. L., Lang, J.: Standardisation of the oral glucose tolerance test and the criteria for diagnosis of chemical diabetes in children. Metabolism 22, 275-282 (1973)

10. Rosenbloom, A. L.: Criteria for interpretation of the oral glucose tolerance tests in children and insulin responses with normal and abnormal tolerance. Metabolism 22, 301-305 (1973)

11. Ehrlich, R.M., Bambers, G.: Immunologic assay of insulin in plasma of children. Diabetes 13, 177-181 (1964)

12. Parker, M.L., Pildes, R.S., Chao, K.L., Cornblath, M., Kipnis, D.M.: Juvenile diabetes mellitus, a deficiency in insulin. Diabetes 17, 27-32 (1968)

13. Rosenbloom, A.L.: Insulin responses of children with chemical diabetes mellitus. New Engl. J. Med. 282, 1228-1231 (1970)

14. Grant, D.B.: Serum-insulin levels in children during glucose tolerance tests. Acta paediat. scand. 57, 297-299 (1968)

15. Grant, D.B.: Fasting serum-insulin levels in childhood. Arch. Dis. Childh. 42, 375 (1967)

16. Chiumello, G., Del Guercio, M.J., Carnelutti, M., Bidone, G.:
Relationship between obesity, chemical diabetes and beta pancreatic function in children. Diabetes 18, 238-243 (1969)

17. Drash, A.: Chemical diabetes mellitus in the child. Metabolism 22, 255-267 (1973)

18. Balsam, M.J., Kaye, R., Barker, L.: Chemical diabetes in children: Glucose tolerance tests. Metabolism 22, 283-288 (1973)

19. Slone, D., Soeldner, J. S., Steinke, J., Crigler, J. F.: Serum insulin measurements in children with idiopathic spontaneous hypoglycaemia and in normal infants, children and adults. New Engl. J. Med. 274, 820-826 (1966)

20. Rosenbloom, A.L., Wheeler, L., Bianchi, R., Chin, F.T., Tiwary, C. M., Grgic, A.: Age-adjusted analysis of insulin responses during normal and abnormal glucose tolerance tests in children and adolescents. Diabetes 24, 820-828 (1975)

21. Chlouverakis, C., Jarrett, R.J., Keen, H.: Glucose tolerance, age and circulating insulin. Lancet 1967 I, 806-809

22. Boyns, D.R., Crossley, J.N., Abrams, M.E., Jarrett, R.J., Keen, H.: Oral glucose tolerance and related factors in a normal population sample. I. Blood sugar, plasma insulin, glyceride and cholesterol measurements and the effects of age and sex. Brit. med. J. 1969 I, 595-598

23. Welborn, T.A.: Clinical and epidemiological studies of the concentrations of insulin in man. PhD. Thesis, London 1969

24. Welborn, T. A., Stenhouse, N.S., Johnston, C. G.: Factors determining serum-insulin response in a population sample. Diabetologia 5, 263-266 (1969)

25. Florey, C. du V.: Blood glucose, insulin and lipids in Jamaica. An epidemiological study in a rural community. M.D. Thesis, Cambridge 1974

26. Florey, C. du V., Milner, R.D. G., Miall, W.E.: Insulin excess as the initial lesion in diabetes (letter). Lancet 1972 II, 227

27. Spellacy, W. N., Buhi, W.C., Bendel, R.P.: Growth hormone and glucose levels after one year of combination type oral contraceptive treatment. Int. J. Fertil. 14, 51 (1969)

28. Spellacy, W.N., Carlson, K.L., Birk, S.A.: Carbohydrate metabolic studies after six cycles of combined type oral contraceptive tablets. Diabetes 16, 590-594 (1967)

29. Malaisse, W.J., Malaisse-Lagae, F., King, S., Wright, P.H.: Effect of growth hormone on insulin secretion. Amer. J. Physiol. 215, 423-428 (1968)

30. Saez, J.M., Morera, A. M., Bertrans, J.: Plasma concentration of estrone $(E)$ estradiol $\left(E_{2}\right)$ before puberty in humans. $A b-$ stracts of the IVth International Congress of Endocrinology, Washington, June 1972

31. Bidlingmaier, F., Wagner-Barnack, M., Butenandt, O., Knorr, D.: Plasma oestrogens in childhood and puberty under physiologic and pathologic conditions. Pediat. Res. 7, 901-907 (1973)

32. Unger, R.H., Eisentraut, A.M., Madison, L.L., Siperstein, M.D.: Fasting levels of growth hormone in men and women. Nature (Lond.) 205, 804-805 (1965)

33. Franz, A. G., Rabkin, M.T.: Effects of oestrogen and sex differences on secretion of human growth hormone. J. clin. Endocr. 25, 1470-1480(1965)

Received: January 20, 1976, and in revised form: April 26, 1976

Dr. C. du V. Florey

Dept. of Community Medicine

St. Thomas's Hospital Medical School

London, SE $17 \mathrm{EH}$

England 